\title{
Green coffee derived supplements and infusions as a source of polyamines and free amino acids
}

\author{
Lukas Macheiner $^{1}$ (D) Anatol Schmidt ${ }^{1}$ (D) Helmut K. Mayer ${ }^{1}$ (D)
}

Received: 31 January 2020 / Revised: 1 September 2020 / Accepted: 5 September 2020 / Published online: 23 September 2020

(c) The Author(s) 2020

\begin{abstract}
This work reports on monoamines (MA), diamines (DA) and polyamines (PA) as well as free amino acids (fAA) in nutritional supplements and infusions derived from green coffee beans. Samples were investigated using a ultra-high performance liquid chromatography UV/FLR method, which was validated regarding specificity, linearity, range, precision, accuracy and limits of detection and quantification. Nutritional supplements based on green coffee beans showed large amounts of total amines ranging from 1090 to $2593 \mathrm{mg} / \mathrm{kg}$, with exceptional high levels of spermidine up to $724 \mathrm{mg} / \mathrm{kg}$, and a content of fAA from 4004 to $12,389 \mathrm{mg} / \mathrm{kg}$. Infusions brewed from green coffee beans showed much lower contents of amines $(14-17 \mathrm{mg} / \mathrm{L})$ and fAA $(78-100 \mathrm{mg} / \mathrm{L})$. However, if the customary edible portion was considered, infusions from green coffee were a mainly better source for MA and PA as well for fAA, compared to nutritional supplements. Tryptamine and tyramine were predominant as MA putrescine as DA, and spermidine as PA, respectively.
\end{abstract}

\section{Graphic abstract}

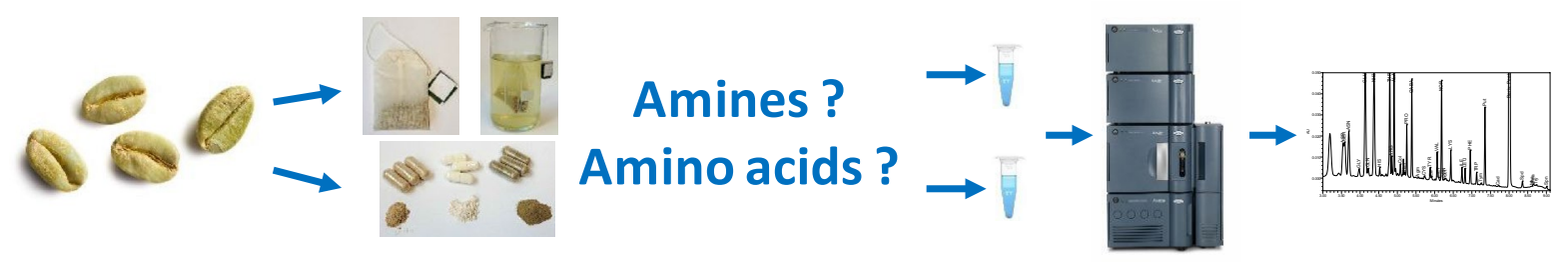

Keywords Nutritional supplements $\cdot$ UHPLC $\cdot$ Monoamines $\cdot$ Diamines $\cdot$ Spermidine

\section{Introduction}

Green coffee beans $(\mathrm{gCB})$ are unroasted seeds from Rubiaceae evergreen shrub genus Coffea. Most harvested and consumed species in the world are represented by Coffea arabica (app. 60\%) and Coffea canephora [1]. Besides being

Electronic supplementary material The online version of this article (https://doi.org/10.1007/s00217-020-03609-6 ) contains supplementary material, which is available to authorized users.

Helmut K. Mayer

helmut.mayer@boku.ac.at

1 Department of Food Science and Technology, Food Chemistry Laboratory, BOKU - University of Natural Resources and Life Sciences Vienna, Muthgasse 11, 1190 Vienna, Austria a food commodity, gCB have recently gained popularity as a novel nutritional source. Nutritional supplements and infusions (bags or powder) for brews of gCB can be found in retail stores and on internet shops. Recent studies report on green coffee beans, powder and derived infusions regarding the contents of chlorogenic acid and caffeine [2,3], trace elements and minerals [4], phenolic [5] and antioxidant compounds [6], as well as possible health hazards due to the presence of mycotoxins [7]. Although numerous studies have investigated the content of free amino acids (fAA) and amines (MA/DA/PA) in $\mathrm{gCB}$, they only did so in regard to possible influences during maturation and harvest [8], postharvest processing [9-12] and roasting [13, 14]. Post-harvest processes can be performed differently, depending on region, water availability, technical opportunities and desired cup 
quality results: wet process, semi-dry process and dry process. In short, the important steps in the wet (post-harvest) process are listed: The pulps are removed mechanically; the remaining mucilage on the beans is cleaved by pectolytic enzymes of microorganisms in a fermentation process, and the washed beans are dried to $10-12 \%$ humidity afterwards on plateaus or in technical applications. In contrast, beans are dried in the entire cherries in the dry (post-harvest) process and the pulps are removed then. The semi-washed or so-called "honey-process" method includes the depulping of coffee cherries and drying of the beans in their surrounding mucilage. The duration of water stress for the plant cells in semi-washed beans is set between wet- and dry-processed beans. Predominant fAA in mature coffee beans before the post-harvest-treatment are glutamic acid, aspartic acid, alanine and asparagine in descending order. C. arabica and C. canephora species show similar compositions, while $C$. canephora species contains generally higher amounts of fAA than $C$. arabica, except glutamic acid. High-content essential fAA in green coffee beans are phenylalanine and tryptophan [15]. Glutamic acid was observed to increase in the wet post-harvest process, while the other former predominant acids showed a decline. The non-protein amino acid gamma amino-butyric acid (GABA) was reported to rise significantly in the dry process. This compound originates from the decarboxylation of glutamic acid in case of drought stress of eukaryotic plant cells and functions as stress metabolite to regulate the osmotic potential in the cells against the decreasing water content [11]. Concerning amines, formation processes were reported to be highly influenced by species and maturation as well as by the choice of the postharvest process. Compounds as putrescine (Put), spermidine (Spd) and spermine (Spn) occur already in cotyledonary leafs and early maturation stages of the seeds (beans) in Coffea [8]. These amines are known to play a crucial role for DNA replication, cell divison, protein synthesis, flower development, and many more essential processes in plant metabolism [16]. Put (as important precursor for Spd and Spn) is formed by the decarboxylation of the amino acids ornithine (ORN) or arginine (ARG). Putrescine was reported to be the main amine of green $C$. arabica beans. According to an earlier study, the formation of putrescine and spermine was proposed to be higher in wet-processed coffee beans than in entire cherry dried beans (dry-processed) [17]. But additionally, overall level of amines was observed to be lower in wet-processed beans. This process was found to have a more uniform drying period and avoided formation of amines like histamine, tyramine and cadaverine [18]. The coffee fermentation is dominated by Enterobacteriaceae and lactic acid bacteria. Decarboxylation of fAA to amines is widely distributed in these microorganisms $[19,20]$. Histamine, tryptamine, cadaverine and high putrescine values were associated to defective beans or low quality. Histamine (causing "scombroid fish poisoning") and tyramine ("cheese reaction") were predominantly investigated in fermented foods and beverages but also in coffee beans ("defects/lowquality indicators") in the past because of their foodborne intoxication effects (nausea, sweating, headache, hyper-/ hypotension) to humans $[18,21,22]$. Thus, amine contents in coffee beans may vary due to many factors as species, variety, origin, degree of ripening and post-harvest process $[17,18,23]$. Additionally, amines like putrescine, histamine, cadaverine, tryptamine and tyramine can also occur during storage or processing because of bacterial/enzymatic or thermal decarboxylation of fAA [20, 23].

According to the European Food Safety Authority (EFSA), histamine and tyramine were defined as most toxic considering food safety aspects. No adverse health effects for healthy individuals could be observed at $50 \mathrm{mg}$ histamine per meal per person [24]. United States Food and Drug Administration (FDA, USA) defined the upper limit of $50 \mathrm{mg} / \mathrm{kg}$ food for histamine [25]. For tyramine, NOAEL limits between $200 \mathrm{mg}$ per oral consumption, and $600 \mathrm{mg}$ per person per meal is reported for persons without monoamine oxidase inhibiting (MAOI) drug treatment in the EU $[24,25]$.

Up till now, no study focused on the nutritional potential of supplements or infusions (e.g., teas) from green coffee ( $\mathrm{gCI}$ ) derived from $\mathrm{gCB}$, regarding fAA and amines. Besides the relevance of AA in daily nutrition, polyamines (PA), such as spermidine (Spd), are presumed to achieve important functions in human metabolism, like autophagy in cells and reduction of blood pressure [26]. Although supplement (Suppl.) and infusion (gCI) products are now available for some years, their possibility as a novel nutritional source of free amino acids and mono-, di- and polyamines has not been investigated yet.

Hence, it was the aim of this study to employ a ultrahigh performance liquid chromatography method (UHPLC) for the determination of fAA and MA, DA and PAin green coffee-derived supplements and green coffee infusions $(\mathrm{gCI})$ to assess their suitability as a nutritional source of fAA and amines.

\section{Materials and methods}

\section{Reagents and standards}

All chemicals and reagents were of analytical grade, and solvents for chromatography of HPLC grade. Ultra-pure water (UHQ) was used for all preparations and was provided by a SG Ultra Clear UC system from Sigma-Aldrich (St. Louis, USA). Sodium acetate ( $\geq 99.5 \%$ ), sodium hydroxide tablets (>99\%) and hydrochloric acid (32\%) were purchased from ROTH (Karlsruhe, Germany). Acetic acid (>99\%) 
was bought from Chem-Lab (Zedelgem, Belgium). Acetonitrile $(\mathrm{AcN})$ was aquired from VWR (Fontenay-sousBois, France) and perchloric acid (>70\%) from Applichem (Darmstadt, Germany). For the L-amino acid standards, such as L-alanine (ALA), L-arginine (ARG), L-aspartatic acid (ASP), L-glutamatic acid (GLU), L-glycine (GLY), L-histidine (HIS), L-isoleucine (ILE), L-leucine (LEU), L-lysine (LYS), L-methionine (MET), L-phenylalanine (PHE), L-proline (PRO), L-serine (SER), L-threonine (THR), L-tyrosine (TYR), L-valine (VAL) and L-cysteine (CYS), a standard mix from Sigma-Aldrich was used. Amino acid standards for L-asparagine (ASN, $\geq 98 \%$ ), L-glutamine (GLN, $\geq 99.5 \%$ ), L-tryptophan (TRP, $\geq 99.5 \%$ ) from Sigma-Aldrich, and L-ornithine (ORN, $\geq 99.5 \%$ ), gamma-aminobutyric acid $(\mathrm{GABA}, \geq 99 \%)$ and norvaline (NOR, $\geq 99 \%$ ) from Fluka (Buchs, Switzerland) were obtained as single standards. Standards for MA, DA and PA: ethanolamine hydrochloride (Col, $\geq 99 \%$ ), histamine dihydrochloride (Him), ethylamine hydrochloride (Ea, $\geq 99 \%$ ), agmatine sulfate salt (Agm, $\geq 97 \%$ ), L-octopamine hydrochloride (Oct, $\geq 99 \%$ ), putrescine dihydrochloride (Put, $\geq 99 \%$ ), 3-methylbutylamine (Mba $\geq 99 \%$ ), tryptamine (Try, $\geq 98 \%$ ), tyramine (Tym, $\geq 99 \%$ ), spermidine trihydrochloride ( $\mathrm{Spd}, \geq 99.5 \%$ ), spermine tetrahydrochloride (Spn, $\geq 99.5 \%$ ), 2-phenylethylamine hydrochloride (Pea, $\geq 99 \%$ ) and cadaverine dihydrochloride ( $\mathrm{Cad}, \geq 99 \%$ ) were purchased from Sigma-Aldrich or Fluka. Standard substances were dissolved in hydrochloric acid $\left(0.1 \mathrm{~mol} \mathrm{~L}^{-1}\right)$. For calibration, a stock standard consisting of all targeted analytes was prepared in hydrochloric acid $\left(0.1 \mathrm{~mol} \mathrm{~L}^{-1}\right)$ and further diluted in in UHQ water to meet the required calibration levels $(1-25 \mathrm{pmol} / \mu \mathrm{L})$. AccQ. Fluor ${ }^{\mathrm{TM}}$ pre-column derivatization kit with borate buffer and 6-aminoquinolyl- $N$-hydroxysuccinimidyl carbamate (AQC) for the derivatization of free amino acids and amines was obtained from Waters (Milford, MA, USA).

\section{Sample acquisition}

Samples (Table 1) of nutritional supplements derived from green coffee (Suppl. 1-7) and ground green coffee beans ( $\mathrm{gCB} 1,3-6$ ) were obtained via Amazon (using the search item "green coffee" in English and German) with the exception of one sample (gCI2), which was purchased in a retail shop (Vienna, Austria). Furthermore, authentic green coffee beans (gCI 7-11) were obtained from a coffee roaster (220GRAD Roesthaus Macheiner KG) in Salzburg

Table 1 Sample list, nutritional green coffee-based supplements—Suppl., green coffee infusion—gCI: additional information on ingredients in supplementary material

\begin{tabular}{|c|c|c|c|c|}
\hline Sample & Origin condition & Additional ingredients / Post-harvest process & Coffea species & Origin \\
\hline Suppl. 1 & GCP Capsules & L-ascorbic acid & - & - \\
\hline Suppl. 2 & GCP Capsules & L-ascorbic acid & - & - \\
\hline Suppl. 3 & GCP Capsules & Cellulose, Mg-stearate, gelatine & - & - \\
\hline Suppl. 4 & GCP Capsules & Cellulose, $\mathrm{Mg}$-stearate & - & - \\
\hline Suppl. 5 & GCP Capsules & Cellulose, L-ascorbic acid & - & - \\
\hline Suppl. 6 & GCP Capsules & $\begin{array}{l}\text { Garcinia cambogia fruit powder, coffee leaves extract, } \mathrm{Zn} \text {-citrate, chromium picolinate, } \\
\text { cellulose, L-ascorbic acid }\end{array}$ & - & - \\
\hline Suppl. 7 & GCP Capsules & $\begin{array}{l}\text { Cocoa extract, caramel (sulphites), caffeine, maltodextrin, guarana extract, Matcha } \\
\text { green tea leaf and bud powder, green tea leaf extract, beet red juice concentrate, } \\
\text { L-ascorbic acid, cayenne powder, defatted cocoa powder, theobromine tapioca starch, } \\
\text { ginger, cinnamon, silicium dioxide, Goji berry, pomegranate seed, Zn-citrate, wheat } \\
\text { grass sprout, alfalfa leaf grass, spinach leaf, broccoli powder, chlorella, spirulina, } \\
D \text { - } \alpha \text {-tocopherol acid succinate, chromium picolinate }\end{array}$ & - & - \\
\hline $\mathrm{gCI} 1$ & Powder & - & - & - \\
\hline $\mathrm{gCI} 2$ & Powder (tea bag) & - & C. arabica & Nicaragua \\
\hline $\mathrm{gCI} 3$ & Powder (tea bag) & - & C. canephora & India \\
\hline $\mathrm{gCI} 4$ & Powder & - & C. arabica & Brazil \\
\hline gCI5 & Powder & - & C. arabica & Honduras \\
\hline gCI6 & Powder & - & C. canephora & India \\
\hline gCI7 & Coffee beans & Wet processed & C. arabica & Ethiopia \\
\hline $\mathrm{gCI} 8$ & Coffee beans & Semi-washed (pulps removed and dried in mucilage) & C. arabica & Brazil \\
\hline $\mathrm{gCI} 9$ & Coffee beans & Wet processed & C. canephora & India \\
\hline $\mathrm{gCI} 10$ & Coffee beans & Wet processed & C. arabica & Colombia \\
\hline gCI11 & Coffee beans & Dry processed & C. arabica & Nicaragua \\
\hline
\end{tabular}

$G C P$ green coffee powder 
(Austria). Infusions of green coffee beans (gCI 1-11) were prepared as suggested by vendors (Supplementary data Fig. S1 B, C) and as published recently [3]. Green coffee beans were ground to powder using a coffee mill (Eureka, Sesto Fiorentino, Italy) with coarseness for espresso machine preparation $\left(x_{50}=250 \mu \mathrm{m}\right.$, determined with analytical sieves).

\section{Preparation of nutritional supplements}

Preparation of nutritional supplements (Suppl.) was derived from a recently published method [27] and was conducted as follows: solid samples (Suppl.) were weighed in $(5.0 \mathrm{~g})$ with an analytical balance (Sartorius, Goettingen, Germany). The extraction of FAA and MA, DA and PA was performed in triplicate. A solid sample was mixed with $0.6 \mathrm{M}$ perchloric acid $(15 \mathrm{~mL})$, shaken for $30 \mathrm{~min}$ at $600 \mathrm{rpm}$ with a Heidolph Unimax 1010 (Schwabach, Germany), and centrifuged for $10 \mathrm{~min}$ at $10.000 \times g$ at $4{ }^{\circ} \mathrm{C}$ (Heraeus Multifuge X3 FR, Hanau, Germany). The supernatant was collected, and the sample was extracted another two times. L-Norvaline standard was added, and the extract brought to a volume of $50 \mathrm{~mL} .1 \mathrm{~mL}$ of the extracted solution was neutralized with $0.54 \mathrm{M} \mathrm{NaOH}(1 \mathrm{~mL})$. Derivatization was carried out with $5 \mu \mathrm{L}$ neutralized sample, $35 \mu \mathrm{L}$ AccQ.Fluor ${ }^{\mathrm{TM}}$ derivatization kit borate buffer, and $10 \mu \mathrm{L}$ of 6 -aminoquinolyl- $N$-hydroxysuccinimidyl carbamate (AQC). The mixtures were vortexed and incubated $1 \mathrm{~min}$ at room temperature, and $10 \mathrm{~min}$ at $55^{\circ} \mathrm{C}$ (Bioer, Sanjay Nagar, Bangalore, India). Derivatized samples were filtered through a $0.20 \mu \mathrm{m}$ syringe filter (Sartorius, Goettingen, Germany) with a $2 \mathrm{~mL}$ inject syringe (Braun Luer Solo, Melsungen, Germany) and brought onto the chromatographic system.

\section{Preparation of liquid samples}

Green coffee infusions ( $\mathrm{gCI}$ ) were produced as recently published by mixing $3.0 \mathrm{~g}$ of green coffee powder with $<200 \mathrm{~mL}$ of hot water for $5 \mathrm{~min}$ [3]. Infusions were then filtered through a $5951 / 2$ filter (Whatman ${ }^{\circledR}$, Marlborough, MA, USA), cooled down to ambient temperature and brought to a volume of $200 \mathrm{~mL}$ using UHQ water. L-Norvaline was added to the filtrate in a $50 \mathrm{~mL}$ flask. Finally, $1 \mathrm{~mL}$ of the solution was centrifuged for $10 \mathrm{~min}$, the supernatant was buffered, and derivatization was performed as described above (see Sect. 2.3).

\section{UHPLC conditions}

Chromatographic separation and analysis of fAA- or MA-, DA- and PA-AQC derivatives was performed on a Waters Acquity ${ }^{\mathrm{TM}}$ Ultra Performance LC (UPLC ${ }^{\mathrm{TM}}$ ) using a serial ultraviolet (UV) and fluorescence (FLR) detection set-up, combining previously published separate UV and FLR set-ups [27, 28], consisting of a Acquity ${ }^{\mathrm{TM}}$ tunable ultraviolet (TUV) and Acquity ${ }^{\mathrm{TM}}$ fluorescence (FLR) detector. Serial instrument set-up was achieved by connecting the FLR detector cell inlet with the TUV detector cell outlet, using PEEK tubing (waters). Separation of target analytes was achieved using a BEH $\mathrm{C}_{18}$ column $(50 \mathrm{~mm} \times 2.1 \mathrm{~mm}$ i.d., $1.7 \mu \mathrm{m}$ ), protected by a $0.2 \mu \mathrm{m}$ in-line filter kit (waters). Gradient elution was conducted at $35^{\circ} \mathrm{C}$, using $0.1 \mathrm{~mol} \mathrm{~L}^{-1}$ sodium acetate in UHQ water, adjusted to a $\mathrm{pH}$ of 4.80 with acetic acid (solvent A), and AcN (solvent B) as recently published [29]. Detection was set at $249 \mathrm{~nm}$ for UV, and at $\lambda_{\mathrm{ex}}=245 \mathrm{~nm}$ and $\lambda_{\mathrm{em}}=395 \mathrm{~nm}$ for FLR detection, using a photomultiplier gain of 2 , at 40 points $\sec ^{-1}$ for UV and FLR. Chromatographic data were processed using Waters Empower $3^{\mathrm{TM}}$, employing smoothing (type: mean, level: 7), and Microsoft Excel 2019 (Redmond, Washington, USA).

\section{Compliance with ethical requirements}

Not applicable. No humans or animal subjects were involved in this study.

\section{Results}

\section{Implementation and validation of the UHPLC-UV-FLR method}

Chromatographic reversed-phase separation of fAA and amines after AQC derivatization has been proposed for coffee [12] and other matrices, using different modes of detection, mostly UV/PDA or FLR. The proposed methodology derives from the experience of the quantification of fAA and amines in soy [27] and dairy products [28] employing similar extraction and derivatization procedures. Using a serial configuration of UV and FLR detection on an UHPLC platform merges the benefits of both modes of detection (Fig. 1), namely easier interpretation and evaluation of chromatograms when using UV detection (based on the similar responses of the targeted analytes), with increased sensitivity and selectivity of FLR detection [29]. To determine the suitability of the proposed methods, validation was carried out regarding: specificity, linearity, range, precision, accuracy, and lower limits of detection (LLOD) and quantification (LLOQ), following international guidelines [30]. Samples Suppl. 5 and gCI11 (Table 1) were chosen to perform recovery experiments. Results of method validation are shown in Table 2. Specificity of the method was ensured by comparing chromatograms obtained from UV detection with the corresponding FLR data. As the offset between the two employed detectors was marginal $(<1 \mathrm{~s})$ due to the relatively high flow rate $\left(1 \mathrm{~mL} \mathrm{~min}{ }^{-1}\right)$, FLR chromatograms were helpful to identify peaks based on their retention behaviour. Linearity was assessed as derived regression 

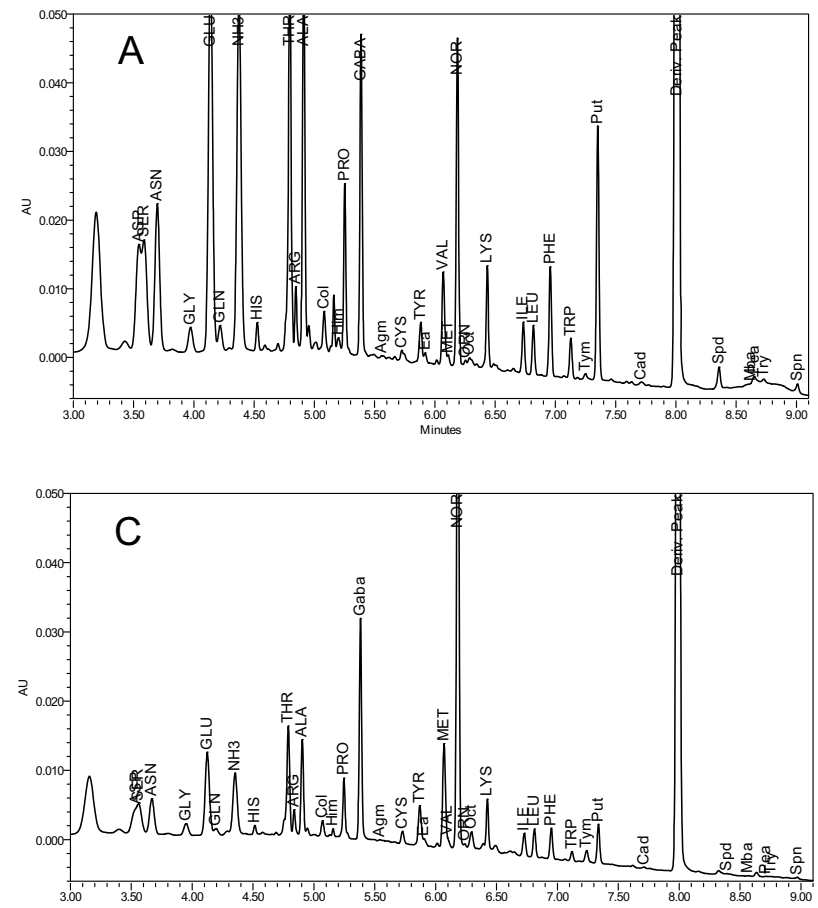

Fig. 1 UHPLC separation with UV $(249 \mathrm{~nm})$ or FLR $\left(\lambda_{\mathrm{ex}}=245 \mathrm{~nm}\right.$, $\lambda_{\mathrm{em}}=395 \mathrm{~nm}$ ) detection of free amino acids and amines in (a) standard separation $(2.5 \mathrm{mM}) \mathrm{UV}$, (b) standard separation $(2.5 \mathrm{mM})$ FLR,

$\left(R^{2}\right)$ on basis of linear dose-response relation of the different concentrations of standards used. With the exception of Spn, all analytes showed a $R^{2}>0.97$ (Table 2), illustrating linearity of the calibration. The AQC-Spn derivate exhibits limited stability [28], which is reflected in the validation data. Similar observations were also made in a previous study [28]. High $\mathrm{pH}$ values (> 8.5) of the AQC-derivatives were suggested for the limited stability of spermine, while the other derivatives showed sufficient stability for analysis. In addition, the stability of polyamines in the food matrix, which were stored in ground form, as also suggested to be highly exposed to enzymatic and/ or microorganism activity. Range of the calibration was set to be from $1 \mathrm{pmol} \mu \mathrm{L}^{-1}$ to $25 \mathrm{pmol} \mu \mathrm{L}^{-1}$ for all targeted analytes. If samples exceeded the highest standard level, samples were diluted prior to derivatization using UHQ water. Precision was assessed as repeatability and intermediate precision of the entire analytical procedure (fAA and amines) for each studied sample matrix (nutritional supplement: suppl., green coffee infusion: gCI). Except for Spn, repeatability ( $n=6$, over 1 day) expressed as the coefficient of variation (CV) of the analytical procedure, ranged from 0.3 to $13.2 \%$ for nutritional supplements, and from 0.2 to $9.9 \%$ for green coffee infusion, respectively. Intermediate precision ( $n=12$ over 4 days, $n=3$ per day, including changed chromatographic solvents) ranged from 0.4 to $15.0 \%$ for nutritional supplements, and from 0.4 to $9.9 \%$ for green coffee infusions, illustrating satisfactory precision of the
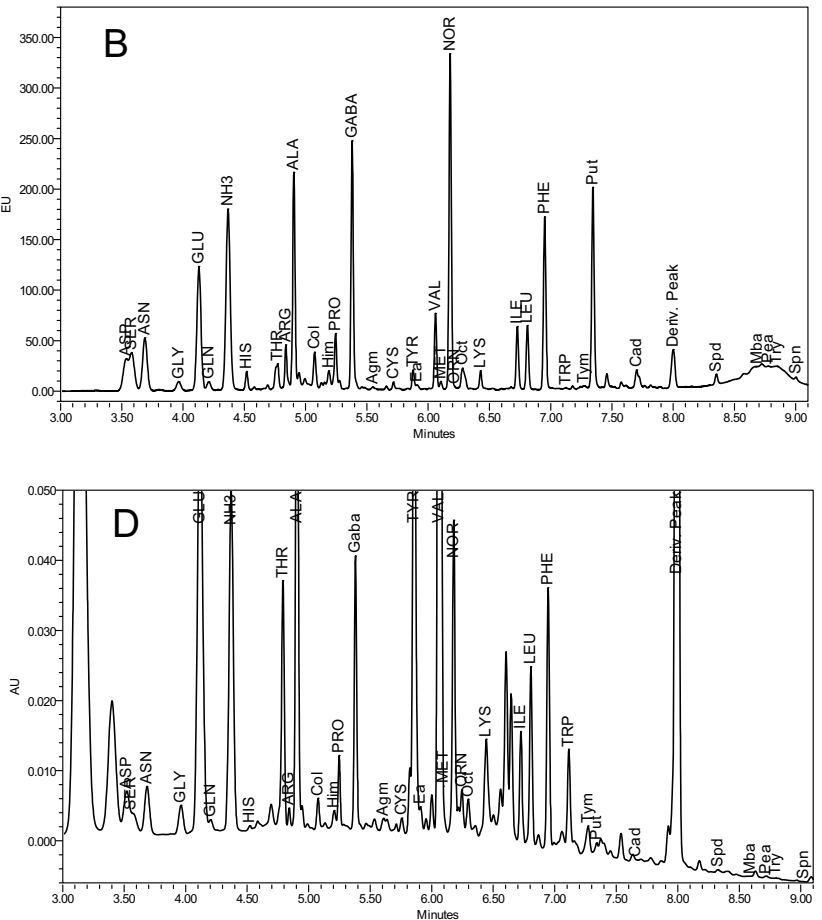

(c) green coffee infusion (gCI11) UV, and (d) nutritional supplement (Suppl. 2) UV

proposed method for the studied matrices. Unfortunately, no comparable data for precision parameters for fAA and amines in nutritional supplements and infusions from green coffee were available at the time of research. Thus, precision limits according to the EU guidelines were calculated [31]. Precision limits of $8 \%$ for supplements and of $16 \%$ for $\mathrm{gCI}$ were set. Hence, gCI CVs offered satisfying results. Precision CVs of the supplement sample validation were slightly above the limits, but rated to be sufficient in an investigation of a challenging food matrix as green coffee. Accuracy of the proposed method was determined by performing recovery experiments for each of the studied matrices. With the exception of GLN, Agm, Ea and Oct, recoveries for fAA and amines ranged from 76.2 to $122.7 \%$ for nutritional supplements, and from 72.5 to $122.4 \%$ for green coffee infusions. No values for recoveries for fAA and amines in nutritional supplements derived from green coffee and green coffee infusions were found in the literature. But according to Q2(R1) guidelines, a range of $70-130 \%$ for the testing of content uniformity was appropriate [30]. Lower limit of detection (LLOD) and lower limit of quantification (LLOQ) were calculated based on signal-to-noise ratio of 3 and 10, respectively, and were found to be satisfactory. LLOQs were calculated for the respective matrices (solid or liquid) and on the basis of the lowest calibration standard (Table 2). Some samples showed levels for fAA and amines below the lowest calibration standards, and thus are only present in traces with 


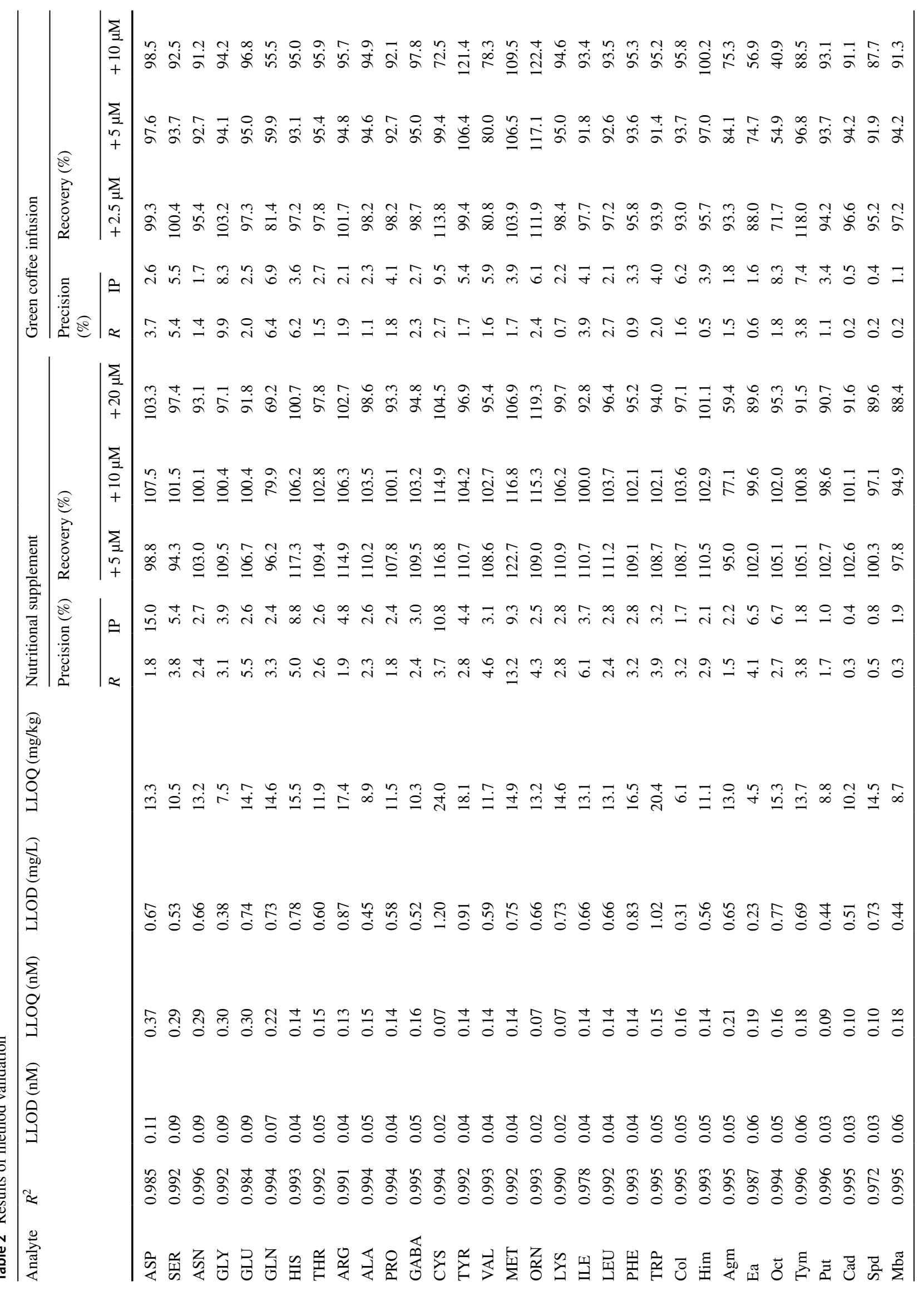


limited nutritional relevance. Corresponding values (between LLOD and LLOQ) are considered to be estimations and are reported without analytical uncertainty. Considering all validation parameters, the proposed method was found to be suitable to study fAA and amines in nutritional supplements as well as infusions from green coffee.

\section{Mono-, di- and polyamines and free amino acids in nutritional supplements}

Green coffee-derived supplements (supplementary data, Fig. S2) gained importance as a source for chlorogenic acids in recent years. Up till now, no data on fAA and amines values for such products were reported. Found levels of fAA in supplements ranged from $4004 \mathrm{mg} / \mathrm{kg}$ (Suppl. 3) up to $12,389 \mathrm{mg} / \mathrm{kg}$ (Suppl. 5) (Table 3), and essential fAA (VAL, ILE, LEU, PHE, TRP, MET, THR, HIS, LYS and ARG) values from $1564 \mathrm{mg} / \mathrm{kg}$ (Suppl. 3) up to $6127 \mathrm{mg} / \mathrm{kg}$ (Suppl. 1). Supplements 6 and 7 contained many additional constituents beside green coffee extract, and are therefore not comparable with other investigated supplements. Additional constituents of samples 6 and 7 like cocoa extract, guarana extract, Goji berry, pomegranate seed, Chlorella and Spirulina are listed (Table 1). Predominant fAA were GLU, VAL, TYR, THR and MET. By considering the values of edible portions (Fig. 2), supplements are mostly exceeded by green coffee infusions, regarding total fAA content. Recommendations by the suppliers of the supplements are given by two capsules per day. Values vary because of different weights of the capsules from $\sim 0.5$ to $1.5 \mathrm{~g}$. Total fAA amounts of Suppl. 3 and 4 were significantly lower. In contrast, supplements 3 and 4 showed highest content of total amines. Determined contents of total amines in supplements ranged from $1090 \mathrm{mg} / \mathrm{kg}$ (Suppl. 2) to $2594 \mathrm{mg} / \mathrm{kg}$ (Suppl. 3). Predominant MA was Try, and predominant PA was Spd. Supplement 3 showed concurrently the lowest total fAA values and the highest total amine values (Tables 3, 4). This trend was also observed for Supplements 1, 5 and 7, which had the highest total fAA amounts but the lower total amine values. Histamine levels ranged from $61.5 \mathrm{mg} / \mathrm{kg}$ (Suppl. 2) to $136.3 \mathrm{mg} / \mathrm{kg}$ (Suppl. 7). Values of spermidine ranged from $248.6 \mathrm{mg} / \mathrm{kg}$ (Suppl. 2) to $724.8 \mathrm{mg} / \mathrm{kg}$ (Suppl. 3). According to other studies, Him, Tym, Cad, Put, and Try can be summarized as amines with adverse health effects [24, 32]. Their cumulative levels in supplements ranged from $401 \mathrm{mg} /$ $\mathrm{kg}$ (Suppl. 2) to $939 \mathrm{mg} / \mathrm{kg}$ (Suppl. 3).

\section{Mono-, di- and polyamines and free amino acids in green coffee infusion}

In addition to nutritional supplements, infusions from green coffee beans were also evaluated. Found total levels of fAA in green coffee infusions ranged from $82.6 \mathrm{mg} / \mathrm{L}(\mathrm{gCI} 7, C$. 


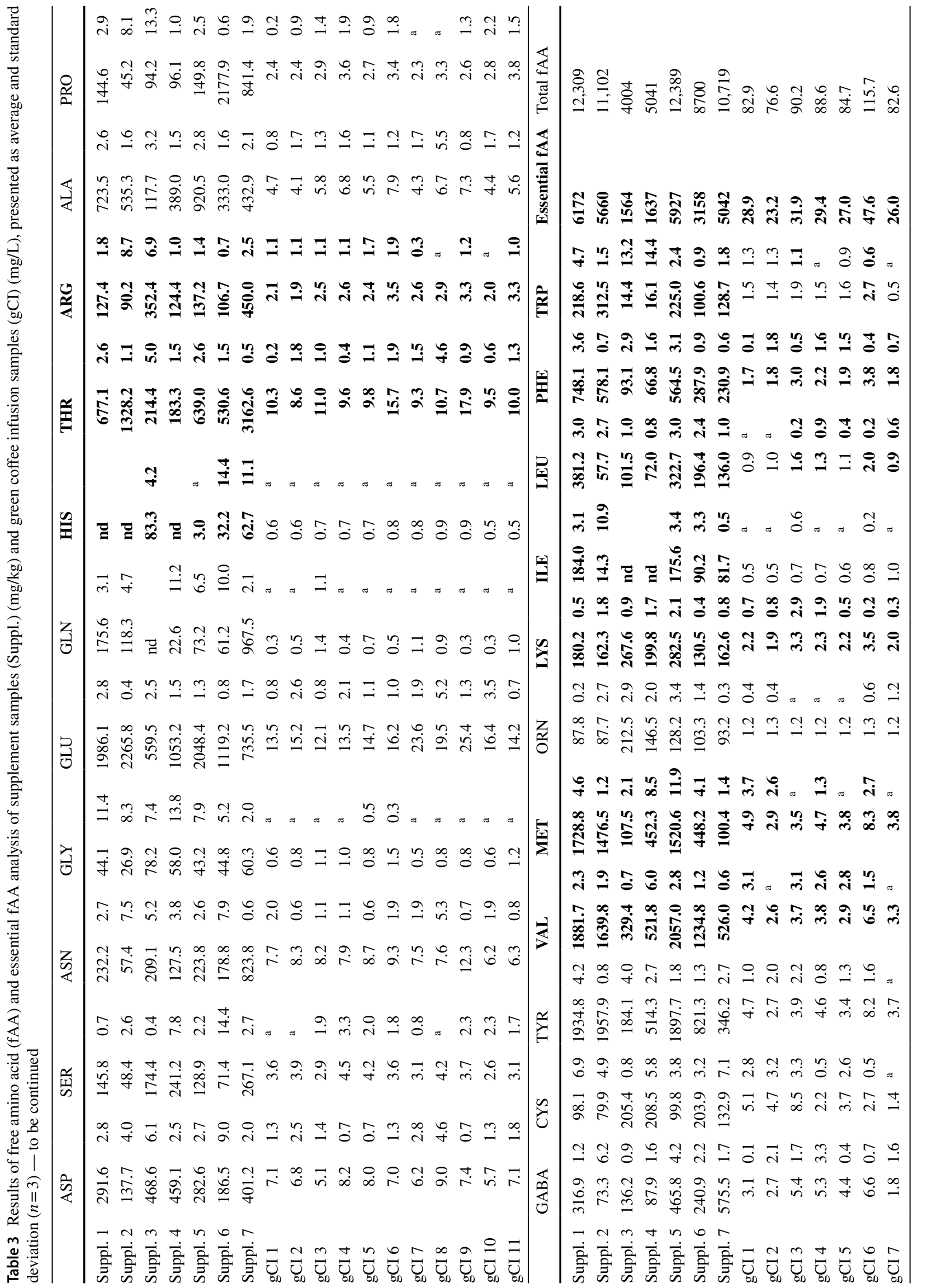




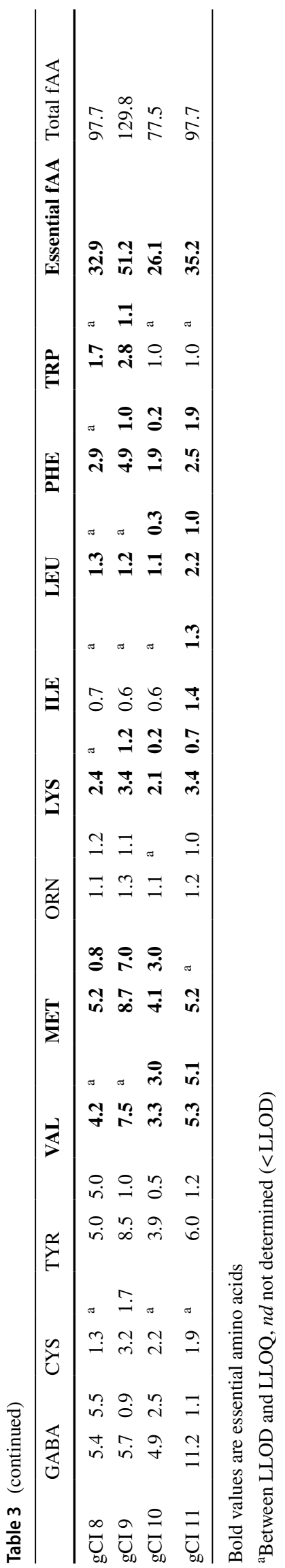

arabica, Ethiopia) to $129.8 \mathrm{mg} / \mathrm{L}$ (gC9, C. canephora, India). Two of the three investigated Indian $C$. canephora samples (gCI6 and 9) exhibited the highest amounts of total fAA. $C$. canephora basis also affected the level of available fAA in infusions typically consumed $(200 \mathrm{~mL})$, which showed a significantly higher content (see Fig. 2, gCI 6 and 9 compared to other gCI). Predominant fAA in infusions were GLU, THR and ASP. Sample gCI11 (C. arabica, Nicaragua) showed the highest GABA amount with $11.2 \mathrm{mg} / \mathrm{L}$. Similar observations for the same coffee species could be observed, with C. canephora samples gCI6 and 9 exceeding all C. Arabica samples regarding the total content of fAA in the final brew. C. canephora sample gCI3 contained lower fAA amount than $\mathrm{gCI} 8$ and $\mathrm{gCI} 11$, but was still in the group of highest gCI fAA amounts. Concerning essential fAA, values between $51.2 \mathrm{mg} / \mathrm{L}$ (gCI9, C. canephora, India) and $23.2 \mathrm{mg} / \mathrm{L}$ (gCI2, C. arabica, Nicaragua) were analysed. Hence, also in case of essential fAA, C. canephora samples gCI6 (47.6 mg/L) and gCI9 (51.2 mg/L) exceeded all C. arabica samples. Found levels of total amines in green coffee brews ranged from $14.4 \mathrm{mg} / \mathrm{L}$ (gCI6, C. canephora, India) to $17.2 \mathrm{mg} / \mathrm{L}$ (gCI11, C. arabica, Nicaragua). Predominant amines were Try and Tym for monoamines, Put for diamines and Spd for polyamines. No discrimination between the investigated gCI samples could be made concerning cumulative levels of amines with adverse health effects (Him, Tym, Cad, Put, and Try), which all of them varied between 6 and $7 \mathrm{mg} / \mathrm{L}$. It has to be considered that samples, which were acquired through retailers (internet or store: gCI 1-6), exhibited limited comparability, as they showed different coarseness of grinding, and may also contained other, not declared components. In addition, bought samples were stored in ground form for unknown periods before the extraction trials in the laboratory. Storage conditions as oxygen environment, humidity and resulting enzymatic activity were unknown. Coffee beans, obtained from a coffee roaster, were not older than a year after the harvest (stored at $10{ }^{\circ} \mathrm{C}$ in protective bags), and were ground on demand for the trials by defined degree of coarseness (described in Sect. 2.2). At least, post-harvest processes of green and moist coffee beans as natural dried, "honey" processed/semi-washed or wet processed have significant impact on fAA and amine contents and ratios $[10,11]$. Post-harvest processes were not declared on the samples from the retail store and the internet. The impact of these processes on coffee beans concerning fAA and amine contents was already published in the past [10], therefore they were not aim of this study. 
Fig. 2 Amounts of free amino acids (fAA) and amines in edible portions of supplements (Suppl., 2 capsules, referring to $0.5-1.5 \mathrm{~g}$ ) and green coffee infusions (gCI, $200 \mathrm{~mL}$ )

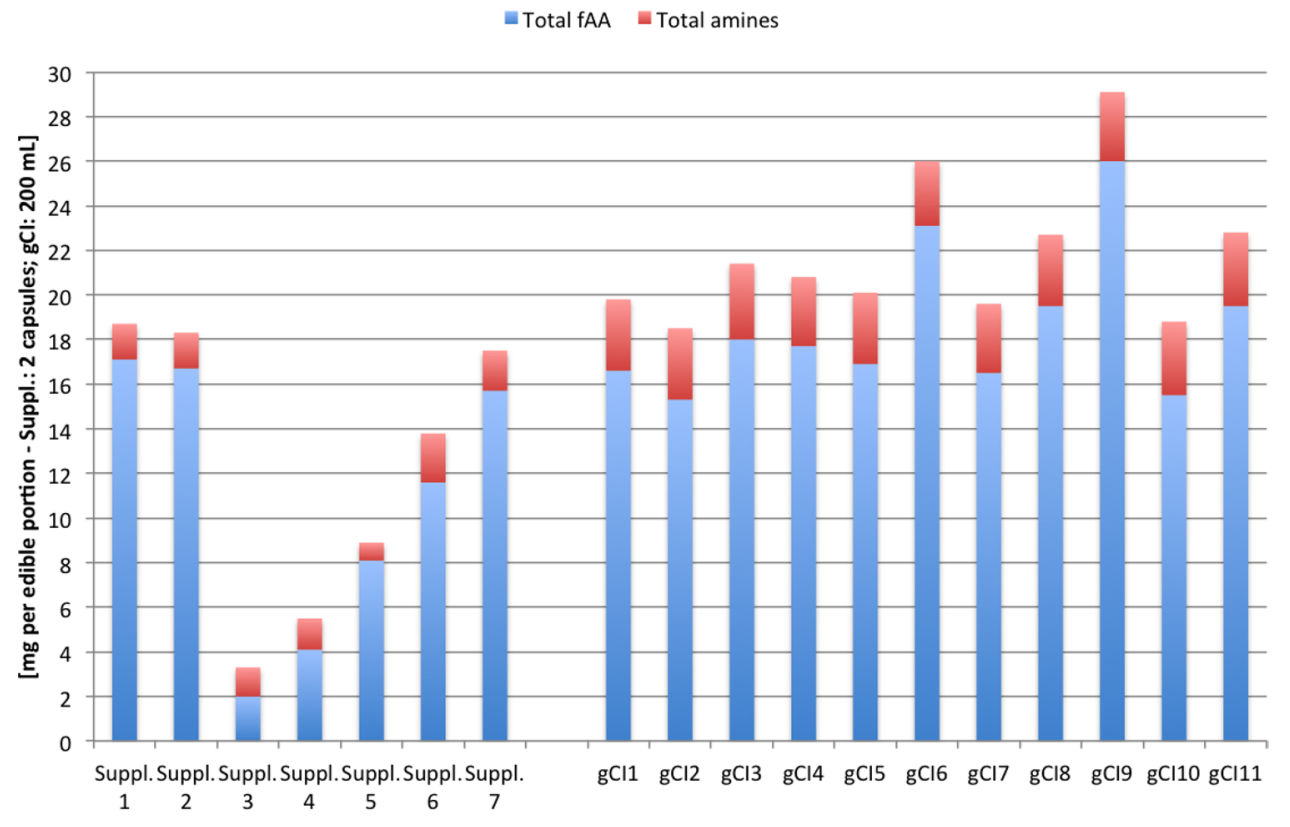

\section{Discussion}

\section{Mono-, di- and polyamines and free amino acids in nutritional supplements}

Surprisingly, in this observation, predominant order of fAA in supplements (GLU, VAL, TYR, THR and MET) differed from the common known abundant fAA in coffee beans [15]: ALA, PRO, ASP, PHE and TRP, except of GLU. Therefore, GLU contents seemed to remain more stable than other fAA during the processing steps of grinding and following storage in oxygen environment. The heat-inducing friction of the beans with the grinding disc in a mill has to be considered at this point. The higher density and hardness of green beans affect a longer stay in the chamber between the grinding discs of the mill to get to the required degree of coarseness. The density of roasted beans is far lower and porosity, therefore, superior due to the crack reaction in the roast process, which increases the bean's volume up to $30 \%$ [33]. The thermal stability of GLU was also observed before in coffee roasting investigations. In contrast, HIS was hardly detectable or only present in low amounts (Table 3), which confirm with corresponding low thermal stability [13]. MET was recorded to be minor-free amino acid in coffee and degraded rapidly by roasting [11, 13, 15]. Surprisingly, in this investigation, high amounts were found in green coffeederived samples.

The typically higher amount of amines in $C$. arabica coffee species is partially due to the particular metabolism of coffee beans for caffeine and amines. Hence, $C$. canephora coffees with their greater amounts of caffeine lack in amine contents. Caffeine synthesis pathway is not fully understood to this day. According to observations in the past, the synthesis of polyamines, caffeine and ethylene in Coffea shrubs is limited by the common precursor $S$-adenosyl-methionine (SAM). Xanthine, as precursor molecule, is methylated in three steps by $N$-methyl-transferases and SAM to 1,3,7-trimethylxanthine, which is commonly known as caffeine. Concerning polyamines, the aminopropyl-group from SAM is needed for further synthesis after the obligatory decarboxylation reaction of amino acids as precursor compounds [34]. Although caffeine was not subject of this study, the higher caffeine contents of $C$. canephora in comparison to $C$. arabica coffees are commonly known and reported $[3,34]$. Total fAA amounts of Suppl. 3 and 4 were significantly lower (Table 3 ), and therefore the total amine contents higher than the other investigated supplement samples (Table 4). This aspect offered an indication for C. arabica basis or a certain proportion of $C$. arabica in supplement samples 3 and 4. Similar observations for the discrimination of $C$. arabica and C. canephora were already published [13, 15]. Providers of capsules missed to declare the species $(C$. arabica or $C$. canephora) of the raw coffee material, and also their post-harvest processing and the geographic origin of the capsules. Therefore, statements about the discrimination of the capsules with regard to $C$. arabica and C. canephora based on the fAA/amine ratio appeared rather speculative without additional information. But supplement samples 3 and 4 offered interesting additional facts to the ratios of fAA and amines: the proportions of essential fAA to the total fAA values with $39.1 \%$ (Suppl. 3) and 32.5\% (Suppl. 4) were lower than the proportions of other supplement samples with 47.8 (Suppl. 5) to 51.0\% (Suppl. 2). The lower percentage of essential fAA in $C$. arabica green coffee beans 


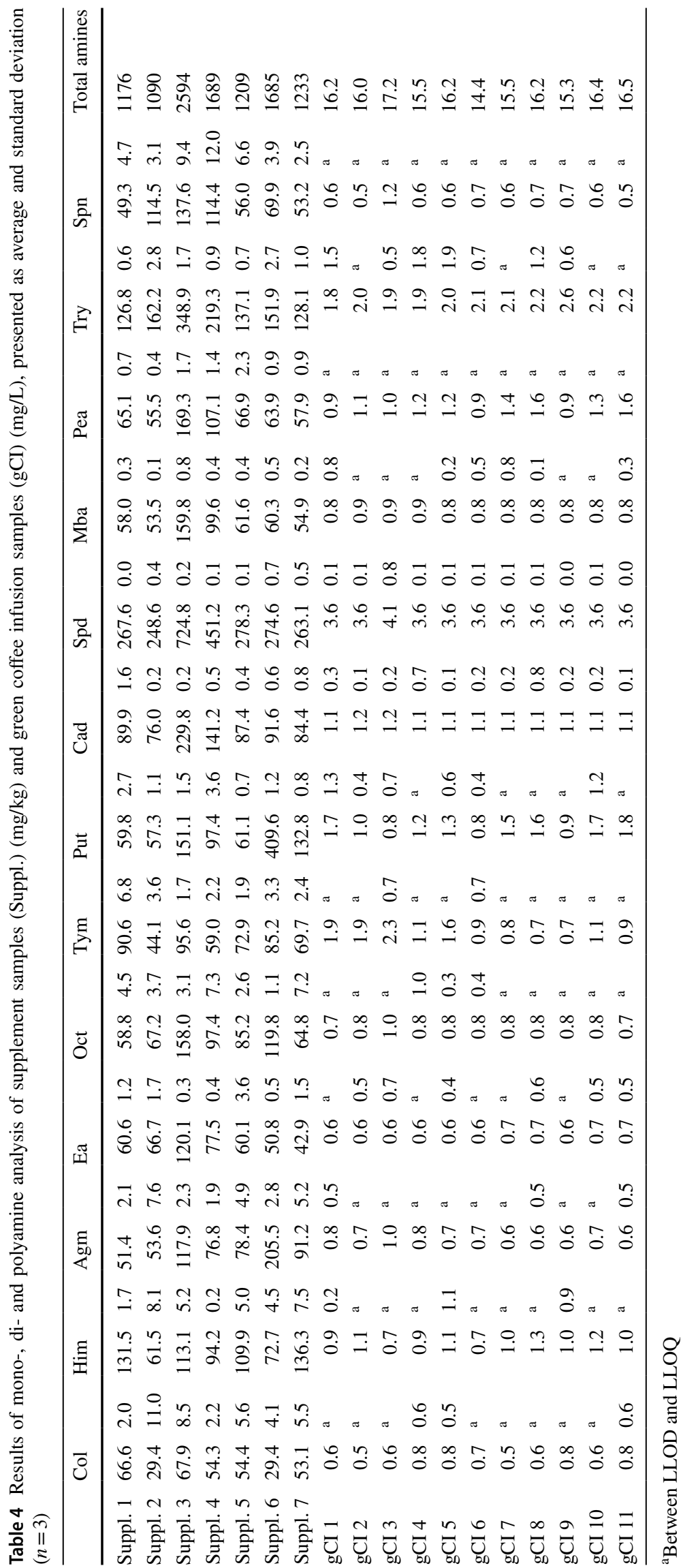


was also reported in the past for THR, VAL, ILE, PHE and TRP [9]. Especially, essential PHE and TRP values (Table 3) were seen to be low in supplement samples 3 and 4, which was also observed in C. arabica beans before [13, 23]. In contrast, amine levels of supplement 3 and 4 exceeded the other samples, considering the fact of limited comparability with supplement sample 6 . To consider nutritional aspects, (non-roasted) green coffee-derived supplements have to be seen as a matrix of fAA and its proteins, due to the fact that supplements are consumed as a whole and without previous processing by the consumer like the extraction for infusions. Hence, when supplements are digested by humans, also proteins are cleaved by proteases and peptidases. Therefore, the overall potential resources of essential AA have to be estimated as higher in supplements than in the aqueous extracts of green coffee infusions. Supplements 3 and 4 contained with $939 \mathrm{mg} / \mathrm{kg}$ and $611 \mathrm{mg} / \mathrm{kg}$ highest cumulative levels of amines with adverse health effects (Him, Tym, Cad, Put, and Try) by excluding samples 6 and 7, whereas the shares of adverse health effect amines to total amines varied between the samples 1 and 5 with $36.2 \%$ (Suppl. 3 and 4 ) and $42.4 \%$ (Suppl. 1). The surprising low shares of adverse health effect amines in supplements 3 and 4 were explained with concomitant appearing high levels of so-called health promoting amines like Spd (Table 4). According to the European Food Safety Authority (EFSA), Him and Tym were defined as most toxic considering food safety aspects. In this investigation, histamine levels ranged from $61.5 \mathrm{mg} / \mathrm{kg}$ (Suppl. 2) to $136.3 \mathrm{mg} / \mathrm{kg}$ (Suppl. 7). In regard to the scientific opinion of EFSA, no adverse health effects for healthy individuals could be observed at $50 \mathrm{mg}$ histamine per meal per person. But NOAEL (no observed adverse effect level) values for persons with histamine intolerance are reported to be under detectable limits [24]. No official suggestions could be found for investigated samples. Observed concentrations of the investigated supplements are clearly below recommended upper limits for persons without histamine intolerance, considering capsules had $0.5-1.5 \mathrm{~g}$ of weight. Tyramine levels ranged from $44.1 \mathrm{mg} / \mathrm{kg}$ (Suppl. 2) to $95.6 \mathrm{mg} / \mathrm{kg}$ (Suppl. $3)$. In the past, general NOAEL values between $200 \mathrm{mg}$ per oral consumption [35] and $600 \mathrm{mg}$ per person per meal [24] were suggested. Considering this, there is no indication for potential intoxication effects caused by tyramine in green coffee-based supplements for healthy individuals not taking monoamine oxidase inhibiting (MAOI) drugs. Even for the NOAEL values of persons who are treated with MAOI drugs (50 mg for MAOI generation 3 and $6 \mathrm{mg}$ for classical MAOI), no acute risk appears by recommended consumptions of one to two capsules per day. Besides the perspective of health risks caused by amines, spermidine was mentioned as cardio-protective and life span prolonging [26]. Additionally, Put, Spd and Spn were reported to be important limiting factors for cell proliferation and regeneration [36].
Results of spermidine ranged from $248.6 \mathrm{mg} / \mathrm{kg}$ (Suppl. 2) to $724.8 \mathrm{mg} / \mathrm{kg}$ (Suppl. 3). The results of total amine contents in supplements significantly exceeded the found values of green coffee infusion samples. But considering edible portions, total amounts of amines in supplements were inferior compared to green coffee infusions (Fig. 2). Amine contents in comparable green coffee-based granules were once published to be $2.91-3.26 \mathrm{mg} / \mathrm{kg}$ for Put, $2.61-3.49 \mathrm{mg} / \mathrm{kg}$ for Spd and $0.20-0.61 \mathrm{mg} / \mathrm{kg}$ for Spn [36]. These data were exceeded by far in this study.

Concerning the bioavailability and digestion of spermidine and spermine, high uptake and recovery rates were reported in the past. Hence, Spd and Spn are well conserved in the body before their utilization as anti-aging and cell regeneration promoters. Put showed only recovery rates up to $15 \%$ in the human body $1 \mathrm{~h}$ after ingestion in previous studies, its majority was already degraded to non-polyamine compounds or metabolized to other polyamines as Spd and Spn $[26,36]$. Hence, in contrast to lower uptake in edible portions compared to infusions, supplements with high Spd and Spn concentrations were suggested to be a promising source due to the high reported bioavailability of Spd and Spn.

\section{Mono-, di- and polyamines and free amino acids in green coffee infusions}

Being a novel food, no comparable data regarding fAA in green coffee infusions were available at the time of writing. The shares of essential fAA to total fAA amounts were the highest in gCI6 and 9 (both C. canephora, India) with $41.1 \%$ and $39.4 \%$. All other samples had shares between $30.3 \%$ (gCI 2, C. arabica, Nicaragua) and 36.0\% (gCI11, C. arabica, Nicaragua). Again high values of THR, VAL, PHE and TRP appeared in C. canephora samples (gCI6 and 9) (Table 3), with exception of gCI3, as seen before in estimated C. canephora supplement samples and in other studies on green coffee beans $[9,13,15]$. Surprisingly, MET values in C. canephora samples gCI6 and 9 significantly exceeded all other samples. In contrast to this study, MET amounts in C. arabica and $C$. canephora green coffee beans were known to be comparable $[9,13]$. Concomitant, higher MET values in C. canephora green coffee beans were also determined in another study [15]. Additionally, by considering extraction aspects, the non-polar character of the MET amino acid side chain seemed to be pushed into higher solubility in water due to the high extraction temperatures between 80 and $100{ }^{\circ} \mathrm{C}$ (water cooled down while the extraction time). At this point, results also contradicted the high sensitivity of MET to heat and oxygen. Consequently, the non-polar character of MET was proposed to be negligible because of the extraction temperature. Higher amounts in C. canephora in the powder derived from green coffee beans confirmed with 
Casal et al. [15]. So green coffee infusions derived from $C$. canephora beans appeared to be on trend, a better source for essential fAA in contrast to $C$. arabica $\mathrm{gCIs}$. This argument was contributed by general higher amounts of total amino acids and the greater share of essential fAA in C. canephora green beans $[9,13,15]$. The non-polar character of most essential fAA seemed to have negligible influence because of high extracting temperatures. Considering again nutritional aspects, fAA in gCI promised some bioavailability promoting factors (digestibility, chemical integrity, freedom of interference). In contrast to supplements, which occurred as solid matrix, $\mathrm{gCI}$ are intended to be consumed as aqueous solution. Therefore, aqueous-solved fAA were estimated to be highly available for the net absorption in the gastrointestinal tract of humans (digestibility). Chemical integrity (proportion of AA in utilizable form in case of absorption) and freedom of interference (by other substances in the related food ingested) were also suggested to be higher in aqueous solutions than in a solid food matrix [37].

Green coffee beans are living organisms like other seeds (e.g., wheat, barley). They are utilized for the plantation of coffee shrubs (Rubiaceae) besides the use to produce roasted coffee [1]. Constituents are also highly impacted by operations after harvesting. Hence, GABA (a non-proteinogenic fAA) is known as an indicator for dry processing of coffee beans in their pulp [11]. This explains the high amounts found of GABA in semi-washed Brazilian (gCI8) and dry post-harvest processed Nicaraguan and $C$. arabica coffee (gCI11). Content of GABA in gCB11 was found to be 11 . $2 \pm 1.1 \mathrm{mg} / \mathrm{kg}$, and significantly exceeded other samples. GABA values for $C$. canephora species correlate well with the general trend of a greater amount of fAA values in $C$. canephora coffees in comparison to C. arabica coffee [13]. High remaining or rising GLU values were reported in wetprocessed coffee beans in the past $[11,38]$. These observations confirmed in this study with wet-processed C. arabica sample gCI7 (Ethiopia) and wet-processed C. canephora sample gCI9 (India) (Table 3). Surprisingly, wet-processed C. arabica sample gCI10 showed comparable GLU values to semi-dry or dry-processed bean-derived infusion samples gCI8 (C. arabica, Brazil) and gCI11 (C. arabica, Nicaragua). The semi-dry post-harvest process was reflected by the second highest amount of GABA and a concomitant high GLU amount in the Brazilian sample (gCI8) (Table 3).

The significant lower amounts of cumulative levels of amines with adverse health effects (Him, Tym, Cad, Put and Try) compared to investigated supplements made any discussion about health hazards regarding amines by consuming green coffee infusions unnecessary. Considering infusion/ brews, only one published Put value of $0.088 \mathrm{mg} / \mathrm{L}$ was reported for an infusion [36]. This literature value was 10to 20 -fold exceeded by values of this investigation. Unfortunately, any statement about the preparation of the infusion in the study [36] was found. To give an overview about products for the same group of consumers, results were also compared to infusions of tea (Camellia sinensis). Reported amounts for Put in C. sinensis ranged from $0.008 \mathrm{mg} / \mathrm{L}$ to $0.021 \mathrm{mg} / \mathrm{L}$, for Spd between 0.007 to $0.011 \mathrm{mg} / \mathrm{L}$, and for Him from 0.011 to $0.020 \mathrm{mg} / \mathrm{L}$ in black tea infusions. Investigations on green tea showed similar result [40]. Hence, found values of amines in green coffee infusions exceeded reported values on infusions of green and black tea leaves by far. As green coffee infusion could be considered an alternative to traditional coffee (from roasted beans), comparison becomes apparent. Found levels of total amines in green coffee slightly exceeded levels of total amines in roasted coffee, prepared using common methods (i.e., Espresso, capsules, pot/Mocha) [41]. Individual levels for Put, Cad, Him, Tym, Spd and Spm in green coffee infusions are well within the range of values reported for roasted coffee [41]. When green coffee infusion was compared to Turkish coffee, total values for amines were exceeded by Turkish coffee. This also applied to individual amines (Put, Cad, Try, Tym). In contrast, Turkish coffee shows negligible amounts of Spd, Spm and Him, which were present in green coffee infusion [42].

\section{Conclusion}

As green coffee products can be found within retail stores and internet shops, they are an emerging novel food. Up till now, no reports on the suitability of nutritional supplements and infusions from green coffee as a nutritional source for total and essential fAA or amines were available. Thus, an UPLC-UV/FLR method was adapted and validated for the investigated matrices. The use of $C$. canephora for green coffee infusions may impact the content of available free amino acids and essential free amino acids positively. In contrast, amine amounts of $C$. arabica mostly exceeded the values of $C$. canephora infusion samples. Further research is needed for final confirmation. Considering edible portions, fAA and amine amounts of supplements were mainly exceeded by the amounts of green coffee infusion samples. In detail, edible portions of supplements were given with 2 capsules (varying between 0.5 and $1.5 \mathrm{~g}$ weight) and of green coffee infusions with $200 \mathrm{~mL}$. The edible portions were derived from supplier's recommendations. The highvolume intake of green coffee infusion compensated the lower measured concentrations of total fAA, essential fAA, and amines (Fig. 2).

Investigated supplements offer high concentrations of spermidine with reported high bioavailability, whereas Spd was found to be consumed in greater amounts by infusions and would be already consumed as solved compound for ingestion. 
Considering health risks, contents of histamine, tryptamine and tyramine are negligible according to the reported data. In the future, extraction efficiencies (considering grinding size, extraction temperature and time, composition of the water solvent) for green coffee infusions have to be the aim of following investigations. In addition to extractability aspects, methods to enhance the bioavailability for ingestion (infusions vs. supplements) are still unexplored fields.

Acknowledgements The authors want also to thank Clemens Gmainer and Iris Biedermann for the skilful technical assistance.

Funding Open access funding provided by University of Natural Resources and Life Sciences Vienna (BOKU).

\section{Compliance with ethical standards}

Conflict of interest LM is a limited partner of a coffee roaster company. AS and HKM declare that they have no conflict of interest.

Compliance with ethics requirements This article does not contain any studies with human participants or animals performed by any of the authors.

Open Access This article is licensed under a Creative Commons Attribution 4.0 International License, which permits use, sharing, adaptation, distribution and reproduction in any medium or format, as long as you give appropriate credit to the original author(s) and the source, provide a link to the Creative Commons licence, and indicate if changes were made. The images or other third party material in this article are included in the article's Creative Commons licence, unless indicated otherwise in a credit line to the material. If material is not included in the article's Creative Commons licence and your intended use is not permitted by statutory regulation or exceeds the permitted use, you will need to obtain permission directly from the copyright holder. To view a copy of this licence, visit http://creativecommons.org/licenses/by/4.0/.

\section{References}

1. Davis AP, Govaerts R, Bridson DM, Stoffelen P (2006) An annotated taxonomic conspectus of the genus Coffea (Rubiaceae). Bot J Linean Soc 152:465-512

2. Jeszka-Skowron M, Sentkowska A, Pyrzyńska K, De Peña MP (2016) Chlorogenic acids, caffeine content and antioxidant properties of green coffee extracts: influence of green coffee bean preparation. Eur Food Res Technol 242(8):1043-1409

3. Macheiner L, Schmidt A, Schreiner M, Mayer HK (2019) Green coffee infusion as a source of caffeine and chlorogenic acid. J Food Compos Anal 84:103307

4. Şemen S, Mercan S, Yayla M, Açikkol M (2017) Elemental composition of green coffee and its contribution to dietary intake. Food Chem 215:92-100

5. Stelmach E, Pohl P, Szymczycha-Madeja A (2015) The content of $\mathrm{Ca}, \mathrm{Cu}, \mathrm{Fe}, \mathrm{Mg}$ and $\mathrm{Mn}$ and antioxidant activity of green coffee brews. Food Chem 182:302-308

6. Castro ACCM, Oda FB, Almeida-Cincotto MGJ, Davanço MG, Chiari-Andréo BG, Cicarelli RMB et al (2018) Green coffee seed residue: a sustainable source of antioxidant compounds. Food Chem 246:48-57
7. Jeszka-Skowron M, Zgoła-Grześkowiak A, Waśkiewicz A, Stépień Ł, Stanisz E (2017) Positive and negative aspects of green coffee consumption - antioxidant activity versus mycotoxins. J Sci Food Agric 97(12):4022-4028

8. Sridevi V, Giridhar P, Ravishankar GA (2009) Endogenous polyamine profiles in different tissues of Coffea sp., and their levels during the ontogeny of fruits. Acta Physiolog Plant 31(4):757-764

9. Arnold U, Ludwig E, Kühn R, Möschwitzer U (1994) Analysis of free amino acids in green coffee beans-I. Determination of amino acids after precolumn derivatization using 9-fluorenylmethylchloroformate. Z Lebens Unters Forsch 199(1):22-25

10. Arnold U, Ludwig E (1996) Analysis of free amino acids in green coffee beans: II. Changes of the amino acid content in arabica coffees in connection with post-harvest model treatment. Z Lebens Untersuch Forsch 203(4):379-384

11. Bytof G, Knopp SE, Schieberle P, Teutsch I, Selmar D (2005) Influence of processing on the generation of $\gamma$-aminobutyric acid in green coffee beans. Eur Food Res Technol 220(3-4):245-250

12. Murkovic M, Derler K (2006) Analysis of amino acids and carbohydrates in green coffee. J Biochem Biophys Methods 69(1-2):25-32

13. Casal S, Mendes E, Oliveira MBPP, Ferreira MA (2005) Roast effects on coffee amino acid enantiomers. Food Chem 89(3):333-340

14. Oliveira SD, Franca AS, Glória MBA, Borges MLA (2005) The effect of roasting on the presence of bioactive amines in coffees of different qualities. Food Chem 90(1-2):287-291

15. Casal S, Alves MR, Mendes E, Oliveira MBPP, Ferreira MA (2003) Discrimination between Arabica and Robusta Coffee species on the basis of their amino acid enantiomers. J Agric Food Chem 51(22):6495-6501

16. Bais HP, Ravishankar GA (2002) Role of polyamines in the ontogeny of plants an their biotechnological applications. Plant Cell Tissue Org Cult 69:1-34

17. Casal S, Mendes E, Rui Alves M, Alves RC, Beatriz M, Oliveira PP, Ferreira MA (2004) Free and conjugated biogenic amines in green and roasted coffee beans. J Agric Food Chem 52:6188-6192

18. Dias E, Pereira RGFA, Borém FM, Mendes E, De Lima RR, Fernandes JO, Casal S (2012) Biogenic amine profile in unripe arabica coffee bens processed according to dry and wet methods. J Agric Food Chem 60:4120-4125

19. Avallone S, Guyot B, Brillouet JM, Olguin E, Guiraud JP (2001) Microbiological and biochemical study of coffee fermentation. Curr Microbiol 42:252-256

20. Halász A, Baráth Á, Simon-Sarkadi L, Holzapfel W (1994) Biogenic amines and their production by microorganisms in food. Trends Food Sci Technol 5:42-49

21. Maintz L, Novak N (2007) Histamine and histamine intolerance. Am J Clin Nutr 85:1185-1196

22. Kovacova-Hanuskova E, Buday T, Gavliakova S, Plekova J (2015) Histamine, histamine intoxication and intolerance. Allergolog Immunopathol (Madr.)

23. Cirilo MPG, Coelho AFS, Araújo CM, Gonçalves FRB, Nogueira GBA (2003) Profile and levels of bioactive amines in green and roasted coffee. Food Chem 82:397-402

24. EFSA (2011) Scientific opinion on risk based control of biogenic amine formation in fermented food. EFSA J 9(10):2393

25. United States Food and Drug Administration (2001) Chapter 7: Scombrotoxin (histamine) formation. In: Fish and fishery products hazards and controls guidance. 4th edn. Washington D.C.: Department of Health and Human Services, Public Health Service, Food and Drug Administration, Center for Food Safety and Applied Nutrition, Office of Food Safety, pp. 113-152 
26. Eisenberg T, Abdellatif M, Schroeder S, Primessnig U, Stekovic S, Pendl T et al (2016) Cardioprotection and lifespan extension by the natural polyamine spermidine. Nat Med 22:1428

27. Sagara T, Fiechter G, Pachner M, Mayer HK, Vollmann J (2017) Soybean spermidine concentration: genetic and environmental variation of a potential 'anti-aging' constituent. J Food Compos Anal 56:11-17

28. Fiechter G, Sivec G, Mayer HK (2013) Application of UHPLC for the simultaneous analysis of free amino acids and biogenic amines in ripened acid-curd cheeses. J Chromatogr B Anal Technol Biomed Life Sci 927:191

29. Fiechter G, Mayer HK (2014) A novel UHPLC method for the determination of amino acids using either fluorescence or ultraviolet detection. Curr Anal Chem 10(3):366-374

30. ICH-Harmonised tripartite guideline (2005) Validation of analytical procedures: text and methodology (Q2)R1

31. European Commission (2002) European Commission decision 2002/657/EC implementing Council directive 96/23/EC concerning the performance of analytical methods and the interpretation of results. Off J Euro Union L 221:8-36

32. Mayer HK, Fiechter G (2018) UHPLC analysis of biogenic amines in different cheese varieties. Food Control 93:9-16

33. Illy A, Viani R (1995) Espresso coffee; the chemistry of quality. Academic Press Limited, London

34. Kumar V, Giridhar P, Chandrashekar A, Ravishankar GA (2008) Polyamines influence morphogenesis and caffeine biosynthesis in in vitro cultures of Coffea canephora P. ex Fr. Acta Physiol Plant 30(2):217-223

35. Paulsen P, Grossgut R, Bauer F, Rauscher-Gabernig E (2012) Estimates of maximum tolerable levels of tyramine content in foods in Austria. J Food Nutri Res 51(1):52-59
36. Bardócz S, Duguid TJ, Brown DS, Grant G, Pusztai A, White A, Ralph A (1995) The importance of dietary polyamines in cell regeneration and growth. Br J Nutr 73:819-828

37. FAO (2013) Dietary protein quality evaluation in human nutrition. Report of an FAO Expert Consultation. FAO Food and Nutrition Paper 92. Rome. ISSN 0254-4725

38. Borém FM (2014) Handbook of coffee post-harvest technology, 1 st edn. Gin Press, Norcross, Georgia

39. Kinnersley AM, Turano FJ (2000) Gamma aminobutyric acid (GABA) and plant responses to stress. Crit Rev Plant Sci 19:479-509

40. Spizzirri UG, Picci N, Restuccia D (2016) Extraction efficiency of different solvents and LC-UV determination of biogenic amines in tea leaves and infusions. J Anal Methods Chem 2016:1-10

41. Restuccia D, Spizzirri UG, Parisi OI, Cirillo G, Picci N (2015) Brewing effect on levels of biogenic amines in different coffee samples as determined as determined by LC-UV. Food Chem 175:143-150

42. Özdestan Ö (2014) Evaluation of bioactive amine and mineral levels in Turkish coffee. Food Res Int 61:67-175

Publisher's Note Springer Nature remains neutral with regard to jurisdictional claims in published maps and institutional affiliations. 